\title{
Decline in Milkweed (Asclepias syriaca) Populations in Central New Jersey over a One Year Period
}

\author{
Nikhil Gopal $^{1, *}$, Jamie Witsen ${ }^{2}$ \\ ${ }^{1}$ The Lawrenceville School, Lawrenceville, New Jersey, USA \\ ${ }^{2}$ Science Department, Montgomery Township Schools, Skillman, New Jersey, USA \\ *Corresponding author: nikhil2@gmail.com
}

Received April 18, 2015; Revised June 01, 2015; Accepted July 05, 2015

\begin{abstract}
Milkweed (Asclepias syriaca) is the primary food source of the eastern North American Monarch butterfly (Danaus plexippus), and numbers have been steadily declining. Between 2012 to 2013 we conducted a survey measure to milkweed numbers in Montgomery Township New Jersey. The purpose of this survey was to examine and measure the change in milkweed numbers after a 1 year period. In October 2012, publicly accessible areas of Montgomery Township were surveyed. This same survey was repeated in 2013, and the change in mean number of milkweed plants per plot recorded. Global positioning satellite data were collected using GPS tracker 1.0 for iPhone. All plots from publicly accessible areas were measured except one plot that was intentionally cultivated. Apart from the single intentionally cultivated plot, only 2 plots remained from the original 30 in the 2012 survey (6\%). From the original 302 stalks, only 87 remained one year later (a decrease of $71.9 \%$ ). A total of 3 new plots were found, indicating new growth. There was a notable decrease in the mean number of milkweed stalks per plot from $2012(10.4 \pm 2.3)$ to $2013(4.3 \pm 2.4)$. This decrease was statistically significant at the $5 \%$ level $(P=0.03958)$. Over a one year period, a statistically significant decline in milkweed plants was observed in central New Jersey. More should be done to conserve milkweed populations.
\end{abstract}

Keywords: milkweed, Asclepias syriaca, monarch butterfly, Danaus plexippus, mitigation, conservation

Cite This Article: Nikhil Gopal, and Jamie Witsen, "Decline in Milkweed (Asclepias syriaca) Populations in Central New Jersey over a One Year Period.” World Journal of Agricultural Research, vol. 3, no. 4 (2015): 119122. doi: 10.12691/wjar-3-4-1.

\section{Introduction}

The eastern North American population of the Monarch butterfly (Danaus plexippus) populations has been steadily declining over the past decade. [1] The common milkweed plant (Asclepias species) is the most important food source of the monarch butterfly in eastern North America. Various hypotheses have been put forth for the decline in the monarch: loss of overwintering grounds in Mexico, habitat loss and climate change. A recent analysis by Flockhart found that the primary reason for monarch decline is due to lower numbers of milkweed plants available for monarchs (due to increasing adoption of genetically modified crops and land-use change) [2].

Surprisingly very few field surveys have been conducted looking at the numbers of milkweed over time. The most important field work has been performed in the midwest. One notable field survey was conducted in Iowa in 1999 and found that the density of milkweed patches were much higher in a roadside setting as compared to a cultivated field. [3] This was followed up with another field survey (also in Iowa) which found a startling decline of $58 \%$ in milkweed numbers over a 10 year period $[4,5]$.

Recently the migration route for monarchs has been accurately mapped using a crowd-sourced method. [6]
Although the main routes for monarchs continue to be in the Midwest, important secondary routes for the eastern North American monarch exist in the eastern and coastal states. Unfortunately we could not find evidence of any recent field based surveys of milkweed numbers in any eastern states. Given the importance of eastern migration routes, we thought that future conservation efforts would not be possible without first quantifying milkweed growth or decline over time.

The primary objective of this experiment was to estimate the numbers of naturally occurring milkweed in a defined area within central NJ over a one year period. The secondary objective was to determine whether levels of milkweed were increasing, decreasing or remaining stable. In order to test our hypothesis, we surveyed milkweed populations in Montgomery Township, New Jersey in October 2012 and again in October 2013.

\section{Methods}

This survey was limited to publicly accessible areas of Montgomery Township, NJ which included all public roadways, parks, municipal buildings, fields and schools. The following variables were measured in each milkweed plot: latitude, longitude, altitude, and number of stalks. For ease of counting and to avoid disturbing growth to 
roots, only the stalks visible from ground-level were included in the counts. The number of stalks in each plot were counted manually. Global positioning satellite (GPS) coordinates were collected using GPS Tracker 1.0 for Blackberry in the 2012 survey and Google Maps for iPhone in the 2013 survey. Data were collected over a two week period from the end of September 2012 to the beginning of October 2012 and again from the end of September 2013 to the beginning of October 2013. Means, range and totals for each plot was calculated using Microsoft Excel.

A sampling time frame from the end of September to beginning of October was chosen for several reasons: 1) we knew that any migrating monarchs would have already passed through the area and 2) this time period was before natural senescence of milkweed occurs but after the spring time when new milkweed sprouts might be visible. We wanted to wait long enough in the season to ensure consistent counting from one year to the next. In the follow-up survey in 2013, care was taken to closely examine the base of each of the stalks in each plots to make sure growth was new and to ensure no senescent plants were present.

It is also important to note that one of the plots (\#1) contained a large number of milkweed stalks $(n=180)$. This plot was intentionally cultivated and grown on school grounds. Hence although it is included in the datasets for completeness sake, it is not included in the data analyses as it does not reflect growth in the wild setting.

\subsection{Statistical Methods}

Values were imported into Excel and analyzed using the Analysis ToolPak. Sample means were analyzed using a two-sample t-test assuming unequal variances. The primary endpoint of interest was the mean number of stalks per plot in 2012 compared to 2013. Along with means, standard deviation, standard error, and the minimum and maximum number of stalks per plot were calculated. The statistical null hypothesis was that the mean number of plants per plot in 2012 was no different from 2013. The alternative hypothesis was that the mean number of plants decreased from 2012 to 2013. A twosample t-test was performed using Excel. A hypothesized mean difference of zero between the two groups (year 2012 and year 2013) was used. Since we hypothesized a directional change in the mean number of plants, a onetailed alpha of $0.05 \%$ was used as a critical value. If the result from the $t$ statistic exceeded the critical value, then the null hypothesis was to be rejected.

\section{Results}

\subsection{Field Survey}

Montgomery Township is a rural community in central New Jersey with an abundance of farms and open space preserves. Two separate field surveys were conducted, the first in 2012 and the second in 2013. Surveys were carried out on foot and by automobile. Land was only surveyed if it was accessible to the public. Milkweed plots that were found on private property, but still visible from the publicly accessible areas of the road were recorded. Public parks, schools and other areas which were open to the public were included in the survey.

A summary of the number of milkweed stalks found in each plots are presented below in Table 1. A total of 30 plots were found and counted in the 2012 survey, and a total of 33 were counted in 2013.

Table 1. Number of Stalks in Each Milkweed Plot 2012-2013

\begin{tabular}{|c|c|c|}
\hline Plot \# & \# Stalks 2012 & \# Stalks 2013 \\
\hline Plot 1 & 180 & NA \\
\hline Plot 2 & 6 & 0 \\
\hline Plot 3 & 3 & 0 \\
\hline Plot 4 & 2 & 0 \\
\hline Plot 5 & 1 & 0 \\
\hline Plot 6 & 7 & 0 \\
\hline Plot 7 & 12 & 0 \\
\hline Plot 8 & 4 & 0 \\
\hline Plot 9 & 16 & 0 \\
\hline Plot 10 & 13 & 0 \\
\hline Plot 11 & 8 & 0 \\
\hline Plot 12 & 4 & 0 \\
\hline Plot 13 & 10 & 0 \\
\hline Plot 14 & 45 & 0 \\
\hline Plot 15 & 50 & 0 \\
\hline Plot 16 & 5 & 0 \\
\hline Plot 17 & 9 & 0 \\
\hline Plot 18 & 10 & 0 \\
\hline Plot 19 & 5 & 0 \\
\hline Plot 20 & 8 & 0 \\
\hline Plot 21 & 1 & 0 \\
\hline Plot 22 & 2 & 0 \\
\hline Plot 23 & 8 & 0 \\
\hline Plot 24 & 1 & 0 \\
\hline Plot 25 & 4 & 0 \\
\hline Plot 26 & 8 & 0 \\
\hline Plot 27 & 15 & 17 \\
\hline Plot 28 & 1 & 0 \\
\hline Plot 29 & 4 & 0 \\
\hline Plot 30 & 40 & 70 \\
\hline Plot 31 & NA & 3 \\
\hline Plot 32 & NA & 26 \\
\hline Plot 33 & NA & 20 \\
\hline
\end{tabular}

The total number of milkweed plots found in 2012 was 30 compared to 33 in 2013. However the total number of plants per plot decreased from 302 in 2012 to 136 in 2013. The minimum, maximum, standard deviation and standard error are also presented in Table 2. Raw outputs from the field survey (including GPS coordinates) have been stored in a publicly available digital repository [7].

Table 2. Descriptive Results from Surveys (2012-2013)

\begin{tabular}{|l|c|c|}
\hline & 2012 Survey & 2013 Survey \\
\hline Total \# of Plots & 30 & 32 \\
\hline Mean \# of stalks/plot & 10.4 & 4.3 \\
\hline Standard deviation & 12.72 & 13.56 \\
\hline Standard error & 2.32 & 2.40 \\
\hline \# of stalks/plot (min, max) & 1,50 & 0,70 \\
\hline Total \# of stalks (all plots) & 302 & 136 \\
\hline
\end{tabular}




\subsection{Statistical Results}

Outputs from the Excel statistical analysis tool are provided below in Table 3. The statistical analyses presented below do not include Plot \#1 because this was an intentionally cultivated and maintained plot. Since the primary objective of this experiment was focused on naturally occurring milkweed, this plot was excluded from statistical analyses. The critical value of $\mathrm{T}$ for this analysis was 1.67109. The test statistic (t) value from this calculation was 1.83183, which exceeded the critical value, and hence the null hypothesis was rejected. The associated $\mathrm{p}$ value was 0.036013 and suggests that there was a significant decline in the mean number of milkweed plots from 2012 to 2013.

Table 3. Statistical Analyses (t-Test Results)

\begin{tabular}{|l|c|c|}
\hline & 2012 Survey & 2013 Survey \\
\hline Mean & 10.4 & 4.3 \\
\hline Variance & 161.82 & 183.74 \\
\hline Number of Observations & 29 & 32 \\
\hline Hypothesized Mean Difference & 0 & \multirow{2}{*}{} \\
\cline { 1 - 2 } Degrees of freedom & 59 & \\
\cline { 1 - 2 } t statistic & 1.831833 & \\
\cline { 1 - 2 } t Critical value & 1.671093 & \\
\cline { 1 - 2 } P value & $\mathbf{0 . 0 3 6 0 1 3}$ & \\
\cline { 1 - 2 } & &
\end{tabular}

A bar chart of the change in the mean number of milkweed stalks per plot from 2012 to 2013 is presented below in Figure 1. An average decrease from 10.4 to 4.3 stalks per plot was observed during this time. This change was statistically significant at the $5 \%$ level $(P=0.036)$.

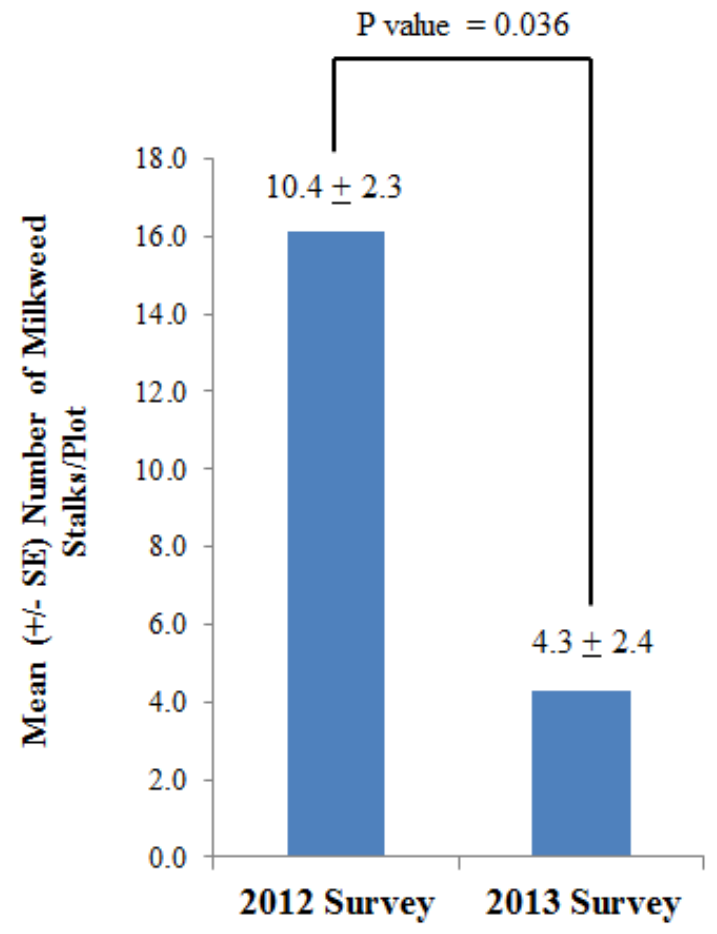

Figure 1. Mean Number of Milkweed Stalks Per Plot by Year

Finally a histogram depicting the distribution of the size of the milkweed plots from the 2012 survey is presented below in Figure 2. This shows that a majority of the plots were of small size (less than 10 stalks). Only a handful of plots were large enough to attract migrating monarchs.
The number of plots available in 2013 were limited (only 5) so a second histogram was not prepared.

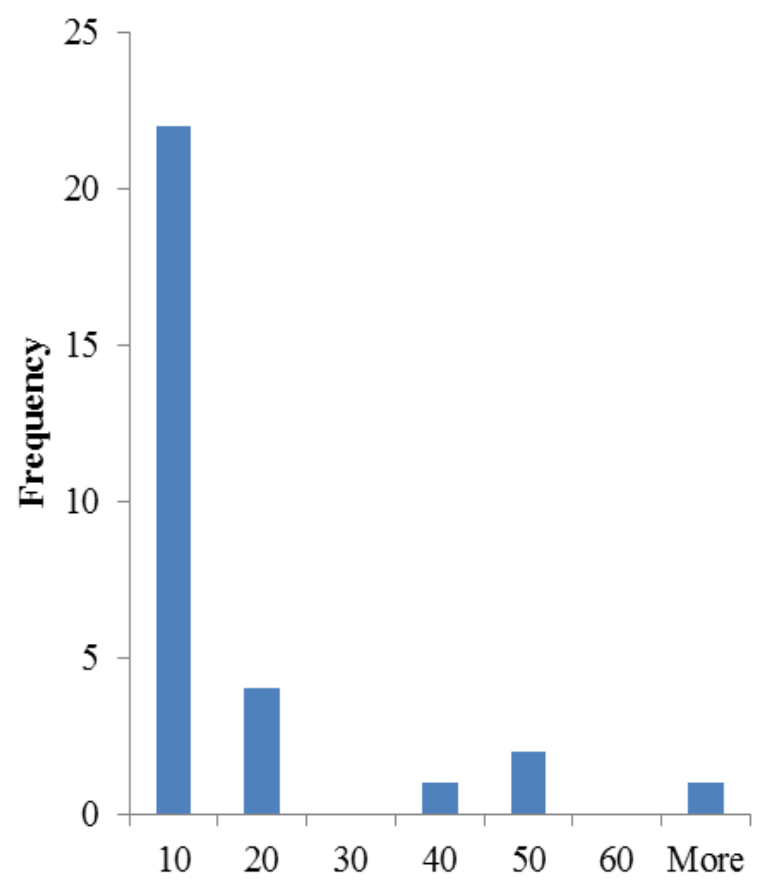

Figure 2. Histogram of Distribution of Stalk Size from 2012 Survey

\section{Discussion}

Based upon our limited survey, it is clear that milkweed populations are decreasing in central New Jersey. There are many potential reasons for this, including the widespread use of roadside mowing and use of herbicides, both of which prevent milkweed to flourish. Unfortunately this survey was not designed to detect causes of this decline, so we can only hypothesize.

We did notice that many of the milkweed plots which were eradicated in 2013 were primarily located near the roadside. The practice of roadside mowing has been controversial and has been linked to the reduction of species richness [8].

There are many limitations with our experiment. Perhaps the biggest limitation of our survey include that we could only survey public areas of the town. Secondly, our survey was limited to a single town which may not accurately represent the state of milkweed populations in all of central New Jersey. It has been estimated that the annual breeding distribution of the eastern North American monarch was 12 million square kilometers. [9] Given that the size of Montgomery Township NJ is only 84 square kilometers, this represents only a small fraction of the spatial scale for the eastern North American monarch. Additionally, no replication was performed in this survey in different counties or regions within central New Jersey. Finally the most important limitation to our experiment was that it was conducted in the fall. Milkweed commonly undergoes normal dieback of the above ground portion (senescence). It is possible that this normal senescence could have influenced our observations; however we took care to ensure that our counts were conducted before the annual fall. Thus we feel that the counts were consistent and accurate from one year to the next. 
The decline of Monarch butterflies has been challenged recently based upon monitoring station data in Cape May NJ and Peninsula Point MI. [10] However because of the large size that is covered by the annual Monarch migration, estimation of overwintering colony areas are the best indicator of Monarch levels [11].

Since our study was not designed to look at butterfly numbers, it is impossible to say whether Monarch levels have decreased. However we provide evidence of a substantial and statistically significant decline in milkweed numbers within central New Jersey.

\section{Conclusions}

A careful review of measures to encourage milkweed re-growth should be performed in order to allow a chance for the eastern North American monarch to recover. Careful management of roadside flowering and milkweeds could contribute significantly to the conservation of monarchs and other pollinating insects.

Further studies should be conducted to see if roadside mowing efforts have hampered the ability for the monarchs to migrate.

More research should be conducted to improve habitats for Monarch caterpillars, and to also encourage milkweed growth. The long term survival of the North American monarch species is at risk.

\section{Acknowledgements}

NG performed the field work and analyzed the data. JW provided guidance during the project and reviewed the manuscript.

This work was submitted to the American Museum of Natural History and received acknowledgement as a finalist in the Young Naturalist Awards 2013. Portions of this work were also presented at the following scientific meetings: 2014 American Society of Plant Biologists Annual Meeting (Portland, OR), 2013 American Society of Plant Biologists Annual Meeting (Providence, RI) and the 2013 Ecological Society of America Annual Meeting (Minneapolis, MN).

The datasets underlying this analysis are available on the Dryad digital repository and can be found at http://dx.doi.org/10.5061/dryad.f16b0.

\section{Statement of Competing Interests}

The authors have no competing interests.

\section{List of Abbreviations}

\author{
GPS: Global Positioning Satellite \\ MI: Michigan \\ MN: Minneapolis \\ NJ: New Jersey \\ OR: Oregon
}

\section{References}

[1] Brower, L.P., Taylor, O.R., Williams, E.H., Slayback, D.A., Zubieta, R.R., and Ramirez, M.I., "Decline of monarch butterflies overwintering in mexico: Is the migratory phenomenon at risk?," Insect Conservation and Diversity, 5 (2): 95-100, 2012.

[2] Flockhart, D., Pichancourt, J.B., Norris, D.R., and Martin, T.G., "Unravelling the annual cycle in a migratory animal: Breeding season habitat loss drives population declines of monarch butterflies,” Journal of Animal Ecology, 84 (1): 155-165, 2015.

[3] Hartzler, R.G., and Buhler, D.D., "Occurrence of common milkweed (Asclepias syriaca) in cropland and adjacent areas," Crop Protection, 19 (5): 363-366, 2000.

[4] Pleasants, J.M., and Oberhauser, K.S., "Milkweed loss in agricultural fields because of herbicide use: Effect on the monarch butterfly population," Insect Conservation and Diversity, 6 (2): 135-144, 2013.

[5] Hartzler, R.G., "Reduction in common milkweed (asclepias syriaca) occurrence in iowa cropland from 1999 to 2009,” Crop Protection, 29 (12): 1542-1544, 2010.

[6] Howard, E., and Davis, A.K., "The fall migration flyways of monarch butterflies in eastern north america revealed by citizen scientists,” Journal of Insect Conservation, 13 (3): 279-286, 2009.

[7] Gopal, N.S., and Witsen, J., "Data from: Field survey results 2012 to 2013 - milkweed populations," Dryad Data Repository.

[8] Persson, T.S., "Management of roadside verges: Vegetation changes and species diversity," Sveriges lantbruksuniversitet, institutionen foer ekologi och miljoevaard (82), 1995.

[9] Flockhart, D.T., Wassenaar, L.I., Martin, T.G., Hobson, K.A., Wunder, M.B., and Norris, D.R., “Tracking multi-generational colonization of the breeding grounds by monarch butterflies in eastern north america," Proceedings of the Royal Society B: Biological Sciences, 280 (1768): 20131087, 2013.

[10] Davis, A.K., “Are migratory monarchs really declining in eastern north america? Examining evidence from two fall census programs," Insect Conservation and Diversity, 5 (2): 101-105, 2012.

[11] Brower, L.P., Taylor, O.R., and Williams, E.H., "Response to davis: Choosing relevant evidence to assess monarch population trends," Insect Conservation and Diversity, 5 (4): 327-329, 2012. 